\title{
LA TUTELA PREVENTIVA DE LA LACTANCIA NATURAL Y DISCRIMINACIÓN POR RAZÓN DE SEXO EN LA PRAXIS JUDICIAL EUROPEA Y NACIONAL: LA INVERSIÓN DE LA CARGA DE LA PRUEBA EN SUPUESTOS DE INCORRECTA EVALUACIÓN DE RIESGOS LABORALES
}

\author{
PREVENTIVE PROTECTION OF BREASTFEEDING AND SEX \\ DISCRIMINATION IN EUROPEAN AND NATIONAL JUDICIAL \\ PRACTICE: REVERSAL OF THE BURDEN OF PROOF IN CASES \\ OF INCORRECT ASSESSMENT OF OCCUPATIONAL RISKS
}

\author{
InMACUlada Marín AlONSO \\ Profesora Titular de Derecho del Trabajo y de la Seguridad Social \\ Universidad de Sevilla \\ ORCID ID: 0000-0002-8871-1020
}

Recibido: 14.01.2019 / Aceptado: 25.01.2019

DOI: https://doi.org/10.20318/cdt.2019.4628

\begin{abstract}
Resumen: Este trabajo muestra cómo el Tribunal de Justicia de la Unión Europea aplica de manera transversal la normativa comunitaria sobre discriminación entre hombres y mujeres en el empleo y la ocupación en relación con la tutela preventiva de las trabajadoras en situación de lactancia natural y con la prestación de seguridad social que cubre dicha contingencia. El Tribunal europeo ha ocasionado un significativo cambio en la doctrina judicial española al considerar que la incorrecta evaluación de riesgos de puestos desempeñados por trabajadoras en situación de lactancia natural es una discriminación directa por razón de sexo. Tal entendimiento conlleva la inversión de la carga de la prueba tanto en el derecho europeo como en el interno, reforzando las garantías procesales de la trabajadora en situación de lactancia. Basta que ésta aporte indicios razonables de riesgos para su seguridad y salud y/o su hijo para que el empleador asuma la carga de demostrar la ausencia del riesgo alegado y la carencia de móvil discriminatorio. Se suaviza o elimina con ello la exigencia de los tribunales internos de acreditar la existencia de un riesgo específico para la lactante y/o su hijo, aplicándose la nueva doctrina tanto a la evaluación del riesgo en el puesto de trabajo desempeñado por la lactante como a las diferentes medidas adoptadas por el empleador para evitar el mismo.
\end{abstract}

Palabras clave: evaluación de riesgos laborales, lactancia natural, inversión de la carga de la prueba, discriminación por razón de sexo.

Abstract: This paper shows how the Court of Justice of the European Union applies Community legislation on discrimination between men and women in employment and occupation in a cross-cutting manner in relation to the preventive guardianship of breastfeeding workers and also to the social security benefit which covers this contingency. The European Court has caused a significant change in Spanish judicial doctrine by considering that the incorrect risk assessment of positions held by breastfeeding workers is discrimination on the basis of sex. Such an understanding implies a reversal of the burden of proof in both European and domestic law, thereby reinforcing the procedural guarantees of the worker. It is sufficient for the latter to provide prima facie evidence of risks to her safety and health and/or her child 
for the employer to assume the burden of proving otherwise and the absence of discriminatory motive. The requirement of the domestic courts to accredit the existence of a specific risk for the breastfeeding worker and/or her child is thus softened or eliminated, applying the new doctrine both to the evaluation of the risk in the job performed by the breastfeeding worker and in the different measures adopted by the employer to avoid it

Keywords: occupational risk assessment, breastfeeding, reversal of burden of proof, sex discrimination.

Sumario: I. La intervención de la doctrina judicial europea en la protección de la seguridad y salud de la trabajadora lactante y su hijo. II. Factores desencadenantes de la "desprotección" de la trabajadora lactante en situación de riesgo en el derecho español III. La interpretación amplia de la protección de la seguridad y salud de la trabajadora lactante: la discriminación por razón de sexo en caso de riesgo para la trabajadora y/o su hijo. IV. El onus probandi en supuestos de discriminación por razón de sexo de la trabajadora en situación de lactancia. V. La protección de la seguridad y salud de la trabajadora lactante en el marco internacional, comunitario y nacional. 1. La tutela preventiva de las trabajadoras lactantes en la LPRL: la evaluación de riesgos 〈específica〉. 2. La dispensa de trabajo y la prestación por riesgo durante la lactancia natural. 3. La certificación médica del riesgo específico. VI. Nuevo reto: los riesgos 〈psicosociales〉 de la trabajadora lactante y su problemática identificación.

\section{La intervención de la doctrina judicial europea en la protección de la seguridad y salud de la trabajadora lactante y su hijo.}

1. En el último quinquenio se han producido numerosos cambios en el ordenamiento jurídicolaboral con ocasión de los pronunciamientos de Tribunales de Justicia Internacionales en nuestra disciplina $^{1}$. En el marco de los derechos relacionados con la situación de maternidad se han pronunciado recientemente tanto el Tribunal de Derechos Humanos -vid sentencia de 24 de enero de 2017, Asunto Paradiso y Campanelli c. Italia, en relación con la maternidad subrogada ${ }^{2}-$, como el Tribunal de Justicia de la Unión Europea -en sentencia de 22 de febrero de 2018, Asunto Porras Guisado, C-103/16 en el ámbito del despido colectivo de trabajadoras embarazadas-, siendo revelador cómo este último Tribunal desempeña un papel cada vez más incisivo en la evolución de los derechos relacionados con la familia y la maternidad en el marco de la Unión Europea.

2. No cabe duda que la protección pública de la mujer trabajadora en situaciones derivadas de la maternidad biológica es una cuestión de especial importancia en el ámbito del Derecho Social europeo, el cual no sólo mira por garantizar la seguridad y salud de la misma en el entorno laboral sino que entronca, además, con medidas de distintos órdenes para aliviar el envejecimiento de la población y la falta de natalidad. La regulación europea ha favorecido la evolución del Derecho Laboral y de Seguridad Social en España en relación a los derechos derivados de la maternidad biológica, la cual se ha inspirado en la regulación comunitaria y ha dado lugar a la metamorfosis del propio concepto de maternidad que, hasta hace poco tiempo, se equiparaba a la situación de enfermedad y formaba parte de la prestación de incapacidad temporal, además de ampliar los supuestos encajables en dicho término. No obstante, la preocupación por proteger la salud de las trabajadoras lactantes en todo lo relacionado con el hecho biológico de la maternidad ha permanecido inamovible durante años tanto por la normativa comunitaria como por la legislación española, siendo esta circunstancia la que, gracias a la doctrina del Tribunal de Justicia de la Unión Europea, ha evolucionado en orden a ampliar las garantías de la mujer trabajadora en dicha situación.

\footnotetext{
1 A título de ejemplo, puede mencionarse, entre otras muchas, la STJUE 13 de mayo 2015, Asunto Rabal Cañas, C-392/13 y STJUE 11 de noviembre 2015, Asunto Pujante Rivera, C-422/14 y C-392/13, sobre el concepto de centro de trabajo a efectos de despidos colectivos; la STJUE 1 diciembre 2016, Asunto Daouidi, C-395/15, en relación con la discapacidad, o la conocida sentencia de 14 de septiembre de 2016, Asunto De Diego Porras, sobre indemnización por extinción contractual, tema sobre la que ha vuelto a incidir la STJUE 21 de noviembre 2018, Asunto Ministerio de Defensa contra A. de D.P, C-619/17.

2 Sobre la maternidad subrogada en el TJUE puede verse la sentencia de 18 de marzo de 2014, Asunto CD, C-167/12 que deniega a una madre subrogante el permiso por maternidad por entender que la maternidad por sustitución no se incluye en el ámbito de aplicación de la Directiva 92/85 aunque la madre subrogante pueda amamantar al niño tras su nacimiento.
} 
3. Conviene señalar que de la situación genérica de maternidad derivan diferentes derechos relacionados con la lactancia de los hijos que, en función del distinto objeto jurídico de protección, tienen una regulación y protección diversa. Así, la lactancia natural deriva exclusivamente de la maternidad biológica y se basa en el derecho de la mujer de alimentar a su hijo mediante dicho sistema, siendo la seguridad y salud de la trabajadora lactante y su hijo el bien jurídico protegido. La preocupación del legislador por la seguridad y salud de la trabajadora y su hijo se centra en tal caso en la lactancia natural o mixta, dejando al margen de la tutela preventiva a la lactancia artificial ${ }^{3}$. En los supuestos en que la trabajadora no opta por la lactancia natural, los derechos relacionados con esta situación giran en torno a la necesaria conciliación de la vida familiar y personal de las personas trabajadoras, donde el principio de igualdad entre hombres y mujeres hace que ese bien jurídico se articule de manera igualitaria entre padres y madres trabajadoras ${ }^{4}$.

4. El TJUE ha tenido ocasión de pronunciarse sobre la lactancia en esos dos ámbitos bajo el prisma del principio de igualdad y no discriminación entre mujeres y hombres: uno, en el marco de los derechos de conciliación de la vida familiar y laboral, en su sentencia de 30 de septiembre de 2010, Asunto Roca Álvarez, en relación con el ejercicio del derecho de lactancia del padre y la madre, con independencia de que ésta sea o no trabajadora por cuenta ajena ${ }^{5}$, y otro, en el ámbito del derecho a la seguridad y salud de la trabajadora lactante y su hijo, donde evidencia que el principio de igualdad entre mujeres y hombres no impide valorar las peculiaridades de la mujer trabajadora en la evaluación de los riesgos laborales, en las medidas preventivas y en los mecanismos de indemnización en supuestos de existencia de riesgos para la seguridad y salud de la lactante y su hijo.

3 F. Navarro Nieto, "La problemática jurídica de la prevención de riesgos laborales durante el embarazo y la lactancia natural”, Relaciones Laborales nº 5, 2012, pág. 46; S. RodRíGuEz GonzÁLEZ, "Riesgo laboral durante la lactancia natural: disconformidad sobre la evaluación de los riesgos y carga de la prueba", Trabajo y Derecho n 38, 2018, La Ley 433/2018, pág. 2

4 Las transformaciones sociales que han provocado la desvinculación de la mujer con su papel tradicional de cuidadora exclusiva o principal del entorno familiar tampoco han afectado a la necesaria protección que el hecho biológico del embarazo y la lactancia natural requieren, sino a moldear, en su caso, los derechos de conciliación de la vida familiar y laboral que de tales situaciones se deriva. Al respecto, véase S. OlaRTE ENCABO, "La protección social por maternidad en supuestos de gestación subrogada: ¿la antesala de un cambio jurisprudencial?. A propósito de la STSJ País Vasco de 13 de mayo de 2014”, Revista de Derecho de la Seguridad Social, Laborum no 2, 2015; también, J.L. Monereo Pérez, y M.B. LóPeZ InsúA, "La renovada tutela social de la maternidad en el marco de los derechos de conciliación”, RGDTSS n 43,2016 . Pero las medidas destinadas a proteger la seguridad y salud de la mujer lactante no son, por tanto, actuaciones encaminadas a conciliar la vida familiar y laboral de las personas trabajadoras, sino medidas que tienen por objetivo garantizar la seguridad y salud de las trabajadoras en especiales circunstancias de riesgo, así como la protección de la infancia y la familia. En tal sentido, el objeto de protección en caso de riesgo durante la lactancia natural es, sin duda, la salud de la mujer trabajadora y/o de su hijo y no la corresponsabilidad entre hombres y mujeres en las cargas familiares o la conciliación de la vida familiar y laboral. La titularidad de los derechos encaminados a la protección de la salud relacionadas con el hecho biológico de la lactancia la ostenta únicamente la mujer trabajadora que alimente a su hijo de forma natural o mixta , mientras que la titularidad de los derechos de conciliación familiar y laboral relacionados con la lactancia abarcan, aunque con distinto alcance, a hombres y mujeres como ocurre, por ejemplo, con el disfrute paterno del derecho al permiso de lactancia o, en el caso de la licencia por maternidad, con la diferente duración del permiso de maternidad o paternidad .

5 El TJUE enjuiciaba la conformidad de la redacción previa del art. 37.4 ET con la normativa comunitaria. En la normativa española se atribuía la titularidad a la trabajadora, si bien el permiso podría disfrutarse indistintamente por padre y madre en el caso de que ambos trabajasen, lo que suponía que el trabajador no podría disfrutar del derecho en caso de que la madre no fuese trabajadora; el TJUE declaró dicha regulación contraria a lo dispuesto por el artículo 2, apartados 1, 3 y 4 , y el artículo 5 de la Directiva 76/207/CEE. Sobre este pronunciamiento véase a J. GorelLi HernándEz, "Límites a la conciliación: de las necesidades de flexibilidad a la insuficiencia de las reducciones de jornada”, Trabajo y Derecho 46, 2018, págs. 14 y ss, que señala que con ello se pone fin a una inadecuada manifestación legal de que la conciliación es una actividad que debe recaer sobre las mujeres y se avanza en la dirección más correcta de la corresponsabilidad. En todo caso, advierte que esta reforma no resuelve todos los posibles problemas que pueden plantearse en materia de titularidad de este derecho (v. gr. falta de acuerdo sobre quién disfrutará el permiso), planteando que la posibilidad del reparto del derecho entre ambos facilitaría la corresponsabilidad. En el ámbito público puede verse a J.M. ChAMOrRo GonZÁLEZ, "El permiso de lactancia como un derecho individual del funcionario y la consiguiente intrascendencia de la situación laboral del otro progenitor (a propósito de la sentencia del Tribunal Superior de Justicia de Canarias de 24 de septiembre de 2015 y del caso Maïstrellis, C-222/14)", Actualidad Administrativa n ${ }^{\circ}$ 3, 2016. Véase al respecto la STC 175/2011, completada con la sentencia de 16 de julio de 2015 dictada por el Tribunal de Justicia de la Unión Europea en el caso Maïstrellis, asunto C-222/14, que expresamente «que el derecho parental para cuidado de hijo recién nacido es un derecho individual del funcionario que no puede depender de la situación laboral del otro progenitor».

6 Véase a C. Ferradans Caramés, "Género y prevención de riesgos laborales", $R D S \mathrm{n}^{\circ}$ 53, 2011, pág. 146; R. PoQUET Catalé, "Inexistencia de evaluación de riesgos específica de los puestos de trabajo de las trabajadoras en período de lactancia 
Este último aspecto es el que centrará nuestra atención en las próximas páginas debido a la importante innovación sufrida en esta materia por la STJUE de 19 de octubre de 2017, en el Asunto Elda Otero vs Servicio Gallego de Salud, C-531/15, que ha establecido un nuevo referente en la polémica tutela de las trabajadoras lactantes por los tribunales de nuestro país y cuya doctrina ha sido reafirmada en la STJUE de 19 de septiembre de 2018, Asunto González Castro, C-41/17. La reciente recepción de la doctrina asentada en tales pronunciamientos por nuestro Tribunal Supremo en las sentencias de 3 de abril de $2018^{7}, 26$ de junio de $2018^{8}$ y de 11 de julio de $2018^{9}$ representa el incremento de las garantías procesales establecidas para la trabajadora lactante y su hijo y, como consecuencia, una mayor facilidad para el acceso a la prestación de riesgo durante la lactancia natural que, debido a su carácter subsidiario y complejo ${ }^{10}$, ha tenido hasta el momento un bajísimo índice de disfrute por las trabajadoras lactantes de nuestro país, tal como evidencian las estadísticas oficiales. En concreto, puede verse que en los últimos cuatro años el número de prestaciones ha sido el siguiente ${ }^{11}$ :

\begin{tabular}{|c|c|c|c|}
\hline Total de regímenes & $\begin{array}{c}\mathbf{N}^{\mathbf{0}} \text { medio mensual de } \\
\text { procedimientos iniciados }\end{array}$ & $\begin{array}{c}\mathbf{N}^{\mathbf{0}} \text { de procesos en vigor } \\
\text { al final del período } \\
\text { considerado }\end{array}$ & $\begin{array}{c}\text { Duración media de los } \\
\text { procesos finalizados }\end{array}$ \\
\hline 2018 & 71,8 & 412 & 139,41 \\
\hline 2017 & 66,17 & 422 & 135,59 \\
\hline 2016 & 67,33 & 435 & 134,76 \\
\hline 2015 & 60,33 & 400 & 134,4 \\
\hline
\end{tabular}

Tales datos, sin embargo, combinan mal con la alta conflictividad que esta prestación ha generado en los Tribunales de Justicia españoles, los cuales durante una década han interpretado de manera rigorista la normativa interna sobre la tutela preventiva de la trabajadora lactante. No ha sido hasta el reciente planteamiento de cuestiones prejudiciales ante el Tribunal de Justicia de la Unión Europea por parte de algunos tribunales internos cuando dicha doctrina se ha visto alterada de manera significativa. ${ }^{12}$

\section{Factores desencadenantes de la "desprotección" de la trabajadora lactante en situación de ries- go en el derecho español.}

5. Las dificultades para obtener una protección integral de la trabajadora en situación de lactancia natural se han sustanciado, principalmente, en los siguientes factores: primero, en la complejidad de la evaluación del riesgo 〈específico〉 del puesto de trabajo desempeñado por la trabajadora lactante; segundo, en el carácter subsidiario de la prestación por riesgo durante la lactancia natural y, tercero, en la inexistencia de garantías procesales a favor de la trabajadora lactante para acreditar la existencia de

y discriminación por razón de sexo", Revista Internacional y Comparada de Relaciones Laborales y Derecho del Empleo, $\mathrm{n}^{\mathrm{0}}$ 3, 2018, pág. 173.

7 RJ 2018/1970.

8 Rec. $n^{\circ} 1398 / 2016$.

9 Rec. $n^{\text {o } 396 / 2017 . ~}$

10 De medida última y excepcional la califica I. Beltrán de Heredia Ruiz, "Riesgo específico y suspensión y subsidio por riesgo durante la lactancia", Temas Laborales n 116, 2012, pág. 158.

11 Datos extraídos del Instituto Nacional de Estadística, http://www.seg-social.es.

12 La Sala de lo Social del Tribunal Superior de Justicia de Galicia acordó suspender el procedimiento para elevar una cuestión prejudicial ante el TJUE respecto a si un informe médico de la situación de riesgo presentado por la trabajadora podía constituir un hecho sobre el que presumir una posible discriminación directa o indirecta por razón de sexo. En este proceso, la Sra Otero solicitó a la Dirección Provincial del INSS de A Coruña la certificación médica de riesgo durante la lactancia natural de su hija a efectos de la concesión de la prestación correspondiente de seguridad social. El INSS rechazó su solicitud en base a la evaluación de riegos que declaraba que el puesto desempeñado por la trabajadora era exento de riesgo y el informe del servicio de medicina preventiva que consideró a la trabajadora apta para el servicio. Contra esta denegación la trabajadora interpuso recurso ante el Juzgado de lo Social $\mathrm{n}^{\circ} 2$ de A Coruña, presentando ante dicho órgano un informe de la jefa del servicio de urgencias del centro hospitalario donde trabajaba que indicaba la existencia de riesgos. Tras la desestimación de su recurso en el Juzgado presentó recurso de suplicación ante el Tribunal Superior de Justicia de Galicia. En concreto, véase la STSJ de Galicia de 8 de noviembre de 2017. 
un riesgo para su salud o la de su hijo. Esta última circunstancia ha estado íntimamente ligada a la falta de apreciación por nuestros tribunales de justicia de una posible vulneración del derecho fundamental a la igualdad por razón de sexo ya que daban por hecho que las norma reguladoras en materia preventiva estaban desprovistas de cualquier tipo de discriminación directa o indirecta por dicha causa. No se aplicaba, en consecuencia, el art. 96.1 de la Ley 36/2011, de 10 de octubre, reguladora de la Jurisdicción Social (LRJS en adelante) ${ }^{13}$ respecto de la carga de la prueba en casos de discriminación en relación con el art. 181.2 de la misma ${ }^{14}$, sino que se aplicaba la regla general en materia probatoria según la cual al actor corresponde probar la certeza de los hechos de los que ordinariamente se desprende el efecto jurídico de la demanda (apartados 2 y 3 del art. 217 de la Ley de Enjuiciamiento Civil -LEC, en adelante ${ }^{15}$ - y art. 95 LRJS). Es, precisamente, el cambio que el TJUE opera en la naturaleza del derecho vulnerado el que provocará, a partir de ahora, la aplicación de las medidas procesales protectoras para la trabajadora lactante en materia probatoria.

\section{La interpretación amplia de la protección de la seguridad y salud de la trabajadora lactante: la discriminación por razón de sexo en caso de riesgo para la trabajadora y/o su hijo.}

6. La inclusión de la perspectiva de género en la protección de la seguridad y salud de las trabajadoras lactantes se ha convertido en una seña de identidad en el marco de la Unión Europea. Ello se ha alcanzado a través de la aplicación del principio de igualdad y no discriminación, desempeñando éste un papel fundamental en la evolución jurídico-social de los Estados miembros ${ }^{16}$. Al respecto puede decirse que la inclusión de la perspectiva de género en el marco de la seguridad y salud define a las sociedades avanzadas, motivo por el al ordenamiento jurídico español no le queda más remedio que asumir dicha tendencia y encaminar sus esfuerzos a hacer realidad la aplicación del principio de igualdad y no discriminación en los supuestos de lactancia natural. A ello le conmina el TJUE en dos pronunciamientos recientes: la sentencia de 19 de octubre de 2017, Asunto Elda Otero, C-531/15 y la sentencia de 19 de septiembre de 2018, Asunto González Castro, C-41/17, las cuales entienden que la protección de la seguridad y salud de las trabajadoras en situación de lactancia natural debe realizarse de la manera más extensa posible y sin limitarse a la estricta aplicación de las Directivas existentes en materia de seguridad y salud laboral.

7. La protección integral de las trabajadoras en situación de lactancia natural se ancla en el derecho a la igualdad y no discriminación, el cual es un derecho reconocido en todos los ámbitos jurídicos y órdenes jurisdiccionales, vinculado además al derecho a la tutela judicial efectiva para hacer realidad el mismo ${ }^{17}$. Particularmente importante para nuestro estudio es la Directiva 2006/54/CEE del Parlamento Europeo y del Consejo, de 6 de julio CEE sobre igualdad de oportunidades e igualdad de trato entre hombres y mujeres en asuntos de empleo y ocupación ${ }^{18}$, la cual tiene por objeto "garantizar

13 BOE n 245 de 10 de octubre de 2011.

14 El Tribunal Constitucional entiende que "la prevalencia de los derechos fundamentales del trabajador y las especiales dificultades probatorias de su vulneración en aquellos casos constituyen las premisas bajo las que la jurisprudencia constitucional ha venido aplicando la específica distribución de la carga de la prueba en las relaciones de trabajo", hoy recogida en los arts. 96.1 y 181.2 LRJS (SSTC 38/1981, de 23 de noviembre; 138/2006, de 8 de mayo, y 342/2006, de 11 de diciembre). En el TS pueden verse las sentencia de 20 de enero de 2009 -rec. $n^{\circ}$ 1927/0- de 29 de mayo de 2009 -rec. $n^{\circ} 152 / 08$ - y de 13 de noviembre de 2012 -rec. no $3781 / 11-$

15 Ley 1/2000, de 7 de enero, de Enjuiciamiento Civil publicada en el BOE núm. 7, de 8 de enero de 2000.

16 Véase al respecto, por ejemplo, la STJUE de 14 de julio de 2016, Asunto Ornano, C-335/15.

17 La igualdad de trato y no discriminación se reconoce tanto en la normativa internacional como comunitaria e interna. Así, la Convención Europea para la Protección de Derechos Humanos y Libertades Fundamentales de 1950 y el Pacto Internacional de Derechos Civiles y Políticos de 1966 reconocieron ya ese derecho, siendo el Convenio ${ }^{\circ} 111$ de la OIT de 1958 , relativo a la discriminación en el empleo y la ocupación, el que definió la discriminación como "cualquier distinción, exclusión o preferencia basaba en motivos de [...] sexo [...] que tenga por efecto anular o alterar la igualdad de oportunidades o de trato en el empleo y la ocupación" (art. 1). Incidieron en dicho principio los Convenios n $\mathrm{n}^{\mathrm{0}} 122$ y 156 de la OIT sobre políticas de empleo y trabajadores con responsabilidades familiares. Sobre este principio véase I. MARín Alonso, "El alcance del principio de igualdad y no discriminación en condiciones de trabajo y sus límites en el empleo público: la no portabilidad entre regímenes de personal de distinta naturaleza jurídica”, Revista de Derecho Social nº 84, 2018.

18 DOUE-L-2006-81416. 
la aplicación del principio de igualdad de oportunidades e igualdad de trato entre hombres y mujeres en asuntos de empleo y ocupación" (art 1), entendiendo que la vulneración del mismo puede ser directa o indirecta. La discriminación directa se define como la situación en que una persona sea, haya sido o pudiera ser tratada por razón de sexo de manera menos favorable que otra en situación comparable, mientras que la discriminación indirecta se caracteriza por ser aquella "situación en que una disposición, criterio o práctica aparentemente neutra sitúan a personas de un sexo determinado en desventaja particular con respecto a personas del otro sexo, salvo que dicha disposición, criterio o práctica pueda justificarse objetivamente con una finalidad legítima y que los medios para alcanzar dicha finalidad sean adecuados y necesarios".

8. La jurisprudencia europea insiste en que las reglas del Derecho de la Unión que regulan la igualdad entre hombres y mujeres pretenden proteger a la mujer en todos los aspectos relacionados con la maternidad, sosteniendo que el objetivo perseguido es proteger a las mujeres antes y después del parto, por lo que "el trato menos favorable a una trabajadora debido a su condición de mujer en período de lactancia debe considerarse incluido en el ámbito de aplicación del artículo 2, apartado 2, letra c) de la Directiva 2006/54 y, constituir, por tanto, una discriminación directa por razón de sexo.

En tal sentido, la STJUE de 19 de octubre de 2017, C-531/17, ha introducido como novedad la apreciación de que la ausencia de evaluación de riesgos específica o de evaluación adecuada de los riesgos para la trabajadora lactante implica, por sí misma, la existencia de una posible discriminación directa por razón de sexo al suponer un trato desfavorable para la mujer en dicha circunstancia en relación con otros trabajadores. Esta valoración reviste carácter objetivo y supone como resultado el incremento de las garantías procesales para la trabajadora en situación de lactancia natural. Lo relevante es que la perspectiva de género adquiere un papel trascendental en la doctrina judicial europea más reciente pues la existencia de una posible discriminación por razón de sexo (directa o indirecta) es lo que determina la aplicación de una concreta normativa comunitaria más favorable para la trabajadora lactante. La resolución judicial europea resuelve la polémica protección de la trabajadora lactante en base a la Directiva 2006/54/CE, cuya distinción entre supuestos de discriminación directa e indirecta ha sido recogida por nuestro derecho interno en la LO 3/2007, de igualdad efectiva entre hombres y mujeres ${ }^{19}$.

9. El TJUE advierte que el incumplimiento empresarial de su obligación de seguridad y salud en el caso de trabajadoras en período de lactancia generará la posible apreciación de una causa discriminatoria directa que, por situar a la mujer en una posición de mayor vulnerabilidad o de trato peyorativo respecto de otros trabajadores, permitirá la inversión de la carga de la prueba en los mismos términos que cualquier otro derecho fundamental. Es la protección reforzada de los derechos fundamentales de los trabajadores lo que la doctrina del tribunal europeo extiende a los supuestos de ausencia de valoración específica de los daños que la trabajadora lactante pueda sufrir en el desempeño de su puesto de trabajo. La posible vulneración del principio de igualdad y no discriminación y, conexo al mismo, del derecho a la tutela judicial efectiva, determinará la aplicación de un nuevo sistema indiciario de prueba al objeto de proteger la seguridad y salud de la trabajadora lactante y su hijo. La evolución que sufre este derecho es evidente en la medida que la falta de determinación empresarial de un riesgo específico para la lactancia natural ya no implicará, sin más, la inexistencia de riesgo para la lactante y su hijo.

En consecuencia, la aplicación del principio de igualdad y no discriminación a los supuestos de incorrecta evaluación de riesgos del puesto de trabajo de la trabajadora lactante es el argumento fundamental para alterar el mecanismo probatorio. La conexión con el derecho fundamental a la igualdad y no discriminación producirá, como veremos, un importante resultado: el desplazamiento del onus probandi hacia el empleador.

19 Se entiende por discriminación directa la "situación en que una persona sea, haya sido o pudiera ser tratado por razón de sexo de manera menos favorable que otra en situación comparable", mientras que la discriminación indirecta hace referencia a aquella "situación en que una disposición, criterio o práctica aparentemente neutros sitúan a personas de un sexo determinado en desventaja particular con respecto a personas del otro sexo, salvo que dicha disposición, criterio o práctica pueda justificarse objetivamente con una finalidad legítima y que los medios para alcanzar dicha finalidad sean adecuados y necesarios". 


\section{El onus probandi en supuestos de discriminación por razón de sexo de la trabajadora en situa- ción de lactancia.}

10. La nueva visión del tribunal europeo reflejada en las SSTJUE de 19 de octubre de 2017, $C-531 / 15$ y de 19 de septiembre de 2018,C-41/17, respecto de la posible existencia de discriminación por razón de sexo en el caso de falta de evaluación de riesgos específicos del puesto de trabajo desempeñado por la trabajadora lactante va a exigir la aplicación de la Directiva 2006/54/CEE sobre igualdad de oportunidades e igualdad de trato entre hombres y mujeres en asuntos de empleo y ocupación, sin limitarse a la protección que estas trabajadoras obtengan a través de las Directivas existentes en materia de prevención de riesgos laborales. En concreto, conforme a la doctrina judicial europea, debe aplicarse lo previsto en el art. 19 de la Directiva 2006/54/CEE en relación con la carga de la prueba y, además, lo previsto en nuestro ordenamiento jurídico en la LRJS sobre protección de derechos fundamentales (arts. 96.1 y 181.2).

Al respecto, el apartado 1 del artículo 19 de la mencionada Directiva dispone sobre la carga de la prueba que "los Estados miembros adoptarán con arreglo a sus sistemas judiciales nacionales las medidas necesarias para que, cuando una persona que se considere perjudicada por la no aplicación, en lo que a ella se refiere, del principio de igualdad de trato presente, ante un órgano jurisdiccional $\mathrm{u}$ otro órgano competente, hechos que permitan presumir la existencia de discriminación directa o indirecta, corresponda a la parte demandada demostrar que no ha habido vulneración del principio de igualdad de trato". El apartado 4 a) del mismo precepto señala que esa inversión de la carga de la prueba se aplicará a "las situaciones cubiertas por el artículo 141 del Tratado y, en la medida en que exista discriminación por razón de sexo, por las Directivas 92/85/CEE ${ }^{20}$ y 96/34/CE ${ }^{21}$...”. Por su parte, la LRJS dispone en su art. 96.1 sobre la carga de la prueba en casos de discriminación que "en aquellos procesos en que de las alegaciones de la parte actora se deduzca la existencia de indicios fundados de discriminación por razón de sexo, orientación o identidad sexual, origen racial o étnico, religión o convicciones, discapacidad, edad, acoso y en cualquier otro supuesto de vulneración de un derecho fundamental o libertad pública, corresponderá al demandado la aportación de una justificación objetiva y razonable, suficientemente probada, de las medidas adoptadas y de su proporcionalidad"; en materia de derechos fundamentales, el art. 181.2 LRJS añade, además, que "en el acto del juicio, una vez justificada la concurrencia de indicios de que se ha producido violación del derecho fundamental o libertad pública, corresponderá al demandado la aportación de una justificación objetiva y razonable, suficientemente probada, de las medidas adoptadas y de su proporcionalidad".

Tales disposiciones permiten que la trabajadora lactante pueda, mediante cualquier medio, aportar indicios de que la evaluación de riesgos laborales de su puesto de trabajo no se hizo de manera adecuada conforme a las Directivas comunitarias que regulan la seguridad y salud en el trabajo, siendo el empleador el que, a partir de ese momento, deberá demostrar lo contrario. Recuérdese que la Directiva Marco 89/291/CEE, de 2 de junio, impone al empresario tres obligaciones básicas: garantizar la seguridad y salud de sus trabajadores en todos los aspectos relacionados con el trabajo (art. 5), disponer de una evaluación de los riesgos para la seguridad y salud en el trabajo, incluidos los que se refieren a grupos de trabajadores con riesgos especiales (art. 6) y adaptar el trabajo a la persona (art. 9); mientras que la Directiva 92/85/CEE, de 19 de octubre, para promover la mejora de la seguridad y de la salud en el trabajo de la mujer en situación de riesgo durante la lactancia, señala, por otro lado, que la obligación empresarial de seguridad y salud abarca no sólo la delimitación de toda actividad que pueda presentar un riesgo para la salud de la trabajadora lactante y su hijo sino, también, la determinación de la naturaleza, el grado y la duración de la exposición al riesgo, y el establecimiento de medidas que eviten el mismo (art. 4) ${ }^{22}$.

20 Directiva 92/85/CEE del Consejo, de 19 de octubre de 1992, relativa a la aplicación de medidas para promover la mejora de la seguridad y de la salud en el trabajo de la trabajadora embarazada, que haya dado a luz o en período de lactancia (décima Directiva específica con arreglo al apartado 1 del artículo 16 de la Directiva 89/391/CEE). DOUE-L-1992-81903.

21 Directiva 96/34/CE del Consejo de 3 de junio de 1996 relativa al Acuerdo marco sobre el permiso parental celebrado por la UNICE, el CEEP y la CES.

${ }^{22}$ El art. 4 de la Directiva 92/85/CEE, de 19 de octubre, relativa a la aplicación de las medidas para promover en el trabajo la mejora de la seguridad y de la salud de las trabajadoras embarazadas, que hayan dado a luz recientemente o en período de lactancia, dispone: "Evaluación e información. 1. Para cualquier actividad que pueda presentar un riesgo específico de exposición a alguno de los agentes, procedimientos o condiciones de trabajo cuya lista no exhaustiva figura en el Anexo I, el empresario, directamente o por medio de los servicios de protección y prevención mencionados en el artículo 7 de la Directiva 89/391/CEE, 
11. Tanto la regulación comunitaria como interna en materia probatoria rompen con la regla general establecida en la LEC, esto es, con la premisa de que corresponde al actor probar la certeza de $\operatorname{los}$ hechos $^{23}$ en la medida que el juez no es un interviniente en los hechos controvertidos y resulta necesario aportarle una completa información de los mismos. ${ }^{24}$. No obstante, con carácter excepcional, la ley permite, por un lado, la exoneración de tener que desplegar la actividad probatoria y, por otro, el establecimiento de presunciones. En tal sentido, la LO 3/2007, para la igualdad efectiva entre hombres y mujeres estableció que "cuando las alegaciones del actor se fundamenten en actuaciones discriminatorias por razón de sexo, corresponderá al demandado probar la ausencia de discriminación en las medidas adoptadas y de su proporcionalidad" 25 , provocando así, la inversión de la carga de la prueba, regulada en el art. 96.1 y 181.2 de la LRJS.

Atendiendo a una reiterada jurisprudencia constitucional, esta inversión no es automática sino que "exige al demandante la aportación de indicios suficientes para sostener una sospecha fundada de vulneración de un derecho fundamental, correspondiendo al demandado desvirtuar la anterior presunción acreditando que su decisión atiende a motivos objetivos, razonables y ajenos a cualquier móvil discriminatorio o lesivo" 26 . No basta, al igual que con cualquier otro derecho fundamental, que el trabajador afirme su carácter discriminatorio, sino que ha de acreditar la existencia de indicios que permitan deducir que la vulneración del derecho se ha producido, que genere una razonable sospecha, apariencia o presunción en favor de semejante afirmación; es necesario, por tanto, que la trabajadora en situación de lactancia natural aporte una "prueba verosímil" o "principio de prueba" revelador de la existencia de un panorama discriminatorio de los que surja la sospecha lógica y coherente de una discriminación, sin que sea suficiente la mera afirmación de la vulneración. No obstante, conforme a la doctrina europea en la materia que nos ocupa, tales condicionantes se superan cuando se presenta "un detalle minucioso acerca de las condiciones de empleo de la trabajadora y de cómo las mismas pueden afectar a la lactancia natural"27. En tal caso, la aportación de nuevos elementos de prueba imparciales será suficiente para que la inversión de la carga probatoria se produzca.

deberá determinar la naturaleza, el grado y la duración de la exposición en las empresas o el establecimiento de que se trate, de las trabajadoras a que hace referencia el artículo 2, para poder: - apreciar cualquier riesgo para la seguridad o la salud, así como cualquier repercusión sobre el embarazo o la lactancia de las trabajadoras a que se refiere el artículo 2 ; - determinar las medidas que deberán adoptarse. 2. Sin perjuicio de lo dispuesto en el artículo 10 de la Directiva 89/391/CEE, en la empresa o establecimiento de que se trate, se comunicará a todas las trabajadoras a que se refiere el artículo 2, y a las trabajadoras que puedan encontrarse en una de las situaciones citadas en el artículo 2, y/o a sus representantes, los resultados de la evaluación contemplada en el apartado 1 y todas las medidas relativas a la seguridad y la salud en el trabajo". Entre tales medidas se encuentra la obligación de comunicar a la trabajadora los resultados de la evaluación y todas las medidas implementadas para garantizar su seguridad y salud en el trabajo. Téngase en cuenta que la Directiva 92/85/CEE define a la trabajadora lactante como aquella que comunique su estado al empresario conforme a las disposiciones legales o prácticas nacionales. No obstante, nuestra normativa interna no impone la obligación de comunicar dicha circunstancia al empleador por lo que parece bastar con poner en conocimiento tal hecho al empleador.

23 Según los apartados 2 y 3 de la LEC “corresponde al actor y al demandado reconviniente la carga de probar la certeza de los hechos de los que ordinariamente se desprenda, según las normas jurídicas a ellos aplicables, el efecto jurídico correspondiente a las pretensiones de la demanda y de la reconvención. 3. Incumbe al demandado y al actor reconvenido la carga de probar los hechos que, conforme a las normas que les sean aplicables, impidan, extingan o enerven la eficacia jurídica de los hechos a que se refiere el apartado anterior [...]".

${ }^{24}$ En tal sentido, señala el TS que "la carga de la prueba o, dicho de otra forma, los efectos negativos de la falta de la prueba nada más que entra en juego cuando no hay prueba sobre determinados extremos de hecho, por lo que su infracción únicamente tienen lugar en aquellos casos en los que, teniéndose por no probado un determinado hecho relevante para la resolución de la controversia, el tribunal atribuye los efectos negativos de tal vacío probatorio a la parte a la que no corresponde soportarlo": STS (Sala de lo Civil) de 9 de mayo de 2013 -RJ 2013/3088. En el mismo sentido, SSTS (Sala de lo Civil) de 25 de abril de 2012 -RJ 2012/6100-, de 15 de noviembre de 2012 -RJ 2013/15- y de 27 de septiembre de 2012 -RJ 2012/9707-.

25 Dispone el art. 13 respecto a la prueba que "1. De acuerdo con las Leyes procesales, en aquellos procedimientos en los que las alegaciones de la parte actora se fundamenten en actuaciones discriminatorias, por razón de sexo, corresponderá a la persona demandada probar la ausencia de discriminación en las medidas adoptadas y su proporcionalidad. A los efectos de lo dispuesto en el párrafo anterior, el órgano judicial, a instancia de parte, podrá recabar, si lo estimase útil y pertinente, informe o dictamen de los organismos públicos competentes...". Esta disposición se incorporó al apartado 5 de la LEC.

26 Entre otras, STC 75/2010, de 19 de octubre. También SSTC 146/2014, de 22 de septiembre.

27 SSTS de 3 de abril de 2018 -rec. no 762/2017- y de 26 de junio de 2018 -rec. no 1398/2016-. Vid. STJUE de 19 de octubre de 2017, C-531/15 y STJUE DE 18de septiembre de $2018-C-41 / 17$ - 
12. A este respecto no deja de llamar la atención que nuestros tribunales internos no hubieran considerado por sí mismos esta protección especial para los supuestos de lactancia natural con soporte en el art. 14 de la Constitución española y el art. 17 del Estatuto de los Trabajadores que prohíben, de manera expresa, la discriminación por razón de sexo, siendo importante destacar que este derecho se sitúa por la doctrina constitucional entre el grupo de derechos regidos por la denominada prueba indiciaria, es decir, entre los que la complejidad de su demostración permiten al demandante aportar un panorama indiciario suficiente de que el trato desfavorable sufrido es discriminatorio, permitiendo tales indicios invertir la carga de la prueba y obligar al demandado a demostrar que su comportamiento obedece a una razón objetiva y razonable sin intención discriminatoria. Asimismo, en virtud del derecho a la tutela judicial efectiva, también se habría podido realizar una interpretación amplia de los mecanismos de prueba aportados por las trabajadoras lactantes para demostrar la existencia de riesgo para su salud o la de su hijo, así como, en su caso, dar mayor credibilidad a los conocidos como riesgos psicosociales motivados por las formas de organización del trabajo que, en algunos supuestos, pese a su difícil objetivización y gestión, podrían encajar en los arts. 4 y 6 del RD 39/1997, de 17 de enero, por el que se aprueba el Reglamento de los Servicios de Prevención. El tímido avance que respecto de la tutela de las trabajadoras lactantes supuso en su día la STS de 24 de abril de $2012^{28}$ al afirmar que no existen condiciones de trabajo exentas de riesgo para la lactancia natural, no llegó a instaurar el esperado giro respecto de la doctrina judicial precedente que denegaba sistemáticamente la prestación de seguridad social cuando no se identificaba un riesgo específico para la lactancia natural conforme a la evaluación de riesgos y las certificaciones médicas aportadas por el INSS o las Mutuas .

13. Debe advertirse, sin embargo, que la nueva doctrina sentada por el TJUE no supone una ruptura total con la postura judicial mantenida anteriormente por nuestros tribunales respecto a la acreditación del riesgo específico, sino que meramente introduce la novedad de permitir una valoración "preferente" de otras pruebas presentadas por la trabajadora que podrían conducir a la acreditación del riesgo para la lactante o su hijo. En concreto, la aportación de informes o certificados médicos por parte de la trabajadora que manifieste la presencia de riesgos físicos, químicos, biológicos o psicosociales que afecten a la lactancia natural va a suponer un indicio de que la evaluación de riesgos puede no haberse efectuado adecuadamente por la empresa y, en virtud de ello, se entenderá producida una discriminación por razón de sexo que provoca la inversión de la carga de la prueba, correspondiendo a la parte demandada demostrar que dicha evaluación de riesgos se realizó con arreglo al art. 4 apartado 1 de la Directiva 2006/54/CEE y no se vulneró el principio de no discriminación.

Además, conforme al nuevo criterio procesal también podrá valorarse si las medidas alternativas propuestas por la empresa para evitar un riesgo específico a la seguridad y salud de la trabajadora lactante ex art. 26 de la Ley 31/1995, de 8 de noviembre, de Prevención de Riesgos (en adelante, LPRL) pueden considerarse adecuadas para eludir el riesgo específico acreditado ${ }^{29}$, dejando abierta la posibilidad de aportar indicios de riesgos por parte de la trabajadora que obliguen al empleador a demostrar lo contrario. En tal caso, como señala la STJUE de 18 de septiembre de 2018, Asunto González Castro, incumbe también al empresario acreditar que las medidas de protección eran técnica u objetivamente posibles y podían exigirse razonablemente.

14. Ha sido, en definitiva, la aplicación de normativa europea en materia de igualdad y no discriminación, en concreto la Directiva 2006/54/CE, la base jurídica que ha permitido al TJUE sentar la base de la evolución en el estándar mínimo de prevención para las trabajadoras lactantes y no las Directivas, genérica o específica, en materia prevención de riesgos. Demuestra ello, en definitiva, que el compromiso por la seguridad integral y la promoción de la seguridad y salud en la empresa aún está en proceso de elaboración, siendo la 〈cultura preventiva〉 una asignatura pendiente, sobre todo, cuando se aborda desde la perspectiva de género.

\footnotetext{
28 Rec. no 3650/11.

29 Esta cuestión ya se planteó en la STS de 24 de abril de 2012 -rec. no 818/2011-.
} 


\section{La protección de la seguridad y salud de la trabajadora lactante en el marco internacional, comunitario y nacional.}

15. Pese a que los riesgos para la maternidad y la lactancia natural no tienen por qué ser necesariamente los mismos, es cierto que, al derivar ambas del mismo elemento biológico, las regulaciones internacionales y nacionales suelen contemplar de manera común ambas situaciones y unificar los procedimientos para obtener la certificación de los riesgos en los puestos de trabajo desempeñados por mujeres en tales circunstancias.

16. La institución pionera en la protección de la lactancia natural ha sido la OIT, la cual ha pasado por diversas fases de protección como resultado de la evolución del papel de la mujer en el trabajo. Así, en una primera etapa, se aprecia el establecimiento por este organismo internacional de prohibiciones para la realización de determinados trabajos para la mujer con marcado carácter paternalista ${ }^{30}$; más tarde, establece medidas preventivas de adaptación de las condiciones de trabajo para la mujer embarazada o lactante; $\mathrm{y}$, por último, promociona la igualdad de oportunidades y de trato entre hombres y mujeres, hasta el punto de considerar discriminatoria la existencia de normas protectoras de la mujer si no están vinculadas a la protección de la maternidad ${ }^{31}$. Ejemplo de tales etapas son, por un lado, el Convenio $\mathrm{n}^{\circ} 103$ de la OIT de $1952^{32}$ y la Recomendación 95 sobre protección de la maternidad, que fueron las primeras normas en establecer medidas destinadas a proteger a las trabajadoras en período de lactancia con carácter preventivo ${ }^{33}$, y, por otro lado, el Convenio $\mathrm{n}^{\mathrm{o}} 183$ de la OIT y la Recomendación 191 sobre protección de la maternidad en el año $2000^{34}$, que dieron un paso más al establecer la necesidad de adoptar medidas que garantizaran la evaluación de todo riesgo para la seguridad y salud de la mujer embarazada o lactante y de su hijo en el lugar de trabajo, reconociendo entre las medidas específicas el derecho de la mujer -embarazada o lactante- a recibir comunicación de los resultados de la evaluación de riesgos en su lugar de trabajo y el derecho a la adopción, en caso de determinarse la existencia de un riesgo significativo para su seguridad o salud, de medidas que, bajo presentación de un certificado médico, se refieran a: 1) la eliminación del riesgo; 2) la adaptación de sus condiciones de trabajo; 3 ) el traslado a otro puesto de trabajo cuando la adaptación no sea posible; y 4) una licencia remunerada conforme a la ley y práctica nacional cuando el traslado a otro puesto de trabajo no sea posible ${ }^{35}$.

30 En España, véase el Decreto de 27 de julio de 1957 sobre prohibición a la mujer de determinados trabajos considerados peligrosos o la STC 22/1992, de 14 de diciembre que declara inconstitucional la prohibición del trabajo de la mujer en la mina. En la doctrina, véase JR. Mercader Uguina, "Filantropía, beneficencia y caridad en el primer derecho obrero", REDT $\mathrm{n}^{\mathrm{o}} 137 / 2008$, pág. 27.

31 Sobre esa evolución puede verse, entre otros, a JF. Lousada Arochena, "La protección de la salud de las trabajadoras embarazadas, parturientas o en período de lactancia”, Actualidad Laboral no 38, 1998, pág. 705; DM. CAirós BARRETO "La seguridad y salud laboral de las mujeres trabajadoras", Revista de Relaciones laborales, Lan Harremanak nº 23, 2010, págs. 87; R. Poquet Catalé, “La prestación por riesgo durante la lactancia natural: debate judicial, RDS nº 64, 2013, pág. 154.

32 De 28 de junio de 1952, sobre la protección de la maternidad.

33 Se imposibilita para estas trabajadoras el desempeño de trabajo nocturno, las horas extraordinarias y los trabajos pesados como levantamiento o empuje de peso que supongan un esfuerzo físico excesivo, equilibrio especial o manejo de máquinas de trepidación. Se prevé en estas normas el derecho de la mujer a ser transferida, sin pérdida o reducción de salario, a otro trabajo que no sea perjudicial para su estado.

34 De 15 de junio de 2000, sobre la protección de la maternidad.

35 La mencionada Recomendación aconseja el establecimiento de las medidas anteriores en casos de trabajo penoso que obligue a levantar, empujar, cargar o tirar de cargas manuales, trabajo que exponga a agentes biológicos, químicos o físicos que puedan ser peligrosos para las funciones reproductivas, trabajo que exija particularmente sentido del equilibrio, trabajo que requiera esfuerzo físico por exigir que la mujer permanezca sentada o de pie durante largos períodos o por exponerla a temperaturas extremas o a vibraciones. Sin embargo, es importante señalar que las medidas que se establecen en esta normativa no van dirigidas específicamente a evitar los riesgos a la lactancia natural sino, más bien, a facilitar la misma (v. gr. establecimiento de interrupciones diarias para la lactancia adaptada a necesidades particulares, la posibilidad de su agrupación -al comienzo o final de la jornada para reducir el tiempo de trabajo, favorecer el establecimiento de instalaciones que permitan la lactancia en condiciones de higiene adecuadas en el lugar de trabajo o cerca del mismo, etc..). 
17. En el marco de la normativa comunitaria se crea, también, un extenso acervo jurídico en materia preventiva tras la modificación del Tratado Constitutivo de la CEE por el Acta Única Europea en 1987. Ve la luz, por un lado, la Directiva Marco 89/391/CEE, de 12 de junio de 1989, relativa a la aplicación de medidas para promover la mejora de la seguridad y de la salud de los trabajadores, que establece un régimen jurídico común para todos los trabajadores, de cualquier sector, en materia preventiva, además de establecer la obligación de adaptar el trabajo a la persona y, por otro lado, la Directiva 92/85/CEE del Consejo, de 19 de octubre de 1992, relativa a la aplicación de medidas para promover la mejora de la seguridad y la salud en el trabajo de la trabajadora embarazada, que haya dado a luz o en período de lactancia ${ }^{36}$, que sitúa a las trabajadoras lactantes entre los grupos especialmente sensibles a determinados riesgos y obliga a adoptar medidas relativas a su seguridad y salud sin que ello, a su vez, desfavorezca a las mujeres en el mercado de trabajo ni atente a las expectativas de igualdad de trato entre hombres y mujeres.

La Comisión europea, por otro lado, señaló en la Estrategia de Seguridad y Salud (2002-2006) ${ }^{37}$ que la política comunitaria persigue no sólo la mejora continua del bienestar físico, moral y social en el trabajo sino, también, introducir la perspectiva de género en esta materia de cara a alcanzar la igualdad entre hombres y mujeres en lo relativo a la seguridad y salud en el trabajo, insistiendo en ello el Marco Estratégico de la Unión Europea en materia de salud y seguridad en el trabajo 2014-202038. En esta línea, tanto el Plan Estratégico de Igualdad de Oportunidades 2014-2016 como el de 2018-2021 se propusieron actuar en determinados aspectos de salud laboral desde la perspectiva de género, especialmente mediante acciones de estudio, formación e información sobre salud y prevención de riegos de las mujeres en atención a sus condiciones de trabajo para detectar, prevenir, proteger, mejorar y promocionar su salud laboral, dedicando especial atención a las mujeres en situación de embarazo, parto, postparto y lactancia, y determinando como factor clave para alcanzar sus objetivos, la realización de una adecuada evaluación de riesgos.

18. En el ámbito nacional, la tutela preventiva de la lactancia natural se regula en la LPRL, principalmente, en su art. 26, y se impulsó con la LO 3/2007, de 22 de marzo, para la igualdad efectiva de mujeres y hombres ${ }^{39}$, que la equiparó a la tutela por riesgo durante el embarazo a efectos de suspensión contractual (art. 45.1 d) TRET) y creó la prestación por dicha causa, regulada actualmente en los arts. 186 a 189 del TRLGSS. Veamos brevemente por separado dicha regulación

\section{La tutela preventiva de las trabajadoras lactantes en la LPRL: la evaluación de riesgos «específica〉}

19. Las obligaciones preventivas de las empresas españolas en caso de lactancia natural se sustancian en el art. 26 de la LPRL, el cual también otorga a la evaluación de riesgos un papel fundamental en orden a conocer tales riesgos y su incidencia en la salud de la trabajadora lactante y su hijo a efectos de proporcionar la protección necesaria a los mismos. El empleador tiene la obligación de evaluar, directamente o mediante los servicios de prevención, la naturaleza, el grado y la duración de la exposición de las trabajadoras en período de lactancia a agentes, procedimientos o condiciones de trabajo, encontrándose una lista no exhaustiva de riesgos potenciales en los anexos de la Directiva $92 / 85 / \mathrm{CEE}^{40}$. Es por ello que a la obligación empresarial de evaluar inicialmente los riesgos confor-

36 Esta Directiva es la décima Directiva específica que se elaboró en virtud de los arts. 15 y 16 de la Directiva Marco 89/391/CEE.

37 Comunicación de 11 de marzo de 2002.

38 En España puede verse el Plan de Acción 2017-2018 de la Estrategia Española de Seguridad y Salud 2015-2010.

39 El reconocimiento del derecho a la suspensión contractual por riesgo durante la lactancia natural fue tardío en el ordenamiento interno español pues la Ley 39/1999, de 5 de noviembre, de conciliación de la vida familiar y laboral de las personas trabajadoras sólo incorporó al ordenamiento la suspensión por riesgo durante el embarazo, sin transponer completamente la Directiva 92/85/CEE (art. 11.1).

40 Esta Directiva incorpora dos Anexos (Anexo VII A y B) que recogen una listado no exhaustivo de condiciones de trabajo que podrían, en potencia, dañar a las trabajadoras según factores químicos, físico o biológicos. En el ordenamiento español se incorporaron a través del RD 289/2009, de 6 de marzo, de modificación del RD 39/1997, de 17 de enero, por el que se aprueba el Reglamento de los Servicios de Prevención. 
me al art. $16 \mathrm{LPRL}^{41}$ se le impone, adicionalmente, una evaluación de riesgos adicional o específica de carácter individual en caso de lactancia natural que se sirve para ello de los Anexos VII y VIII del Reglamento de los Servicios de Prevención aprobado por el RD 39/1997, de 17 de enero ${ }^{42}$, y de las Guías u Orientaciones de distintas asociaciones que detallan los posibles riesgos en caso de lactancia natural ${ }^{43}$.

20. La evaluación específica del puesto de trabajo desempeñado por la trabajadora en situación de lactancia natural debe delimitar la naturaleza, grado y duración de la exposición al riesgo, motivo por el que la jurisprudencia de nuestro Tribunal Supremo exige conocer con detalle la naturaleza, extensión, características, tiempo de exposición al riesgo y seguimiento de la existencia del mismo ${ }^{44}$. No resulta suficiente, por tanto, una evaluación de riesgos meramente funcional o por puestos de trabajo sino que la evaluación debe ser específica y concreta para cada mujer según el momento del ciclo biológico en que se encuentre. Así, la evaluación de riesgos del puesto de trabajo que desempeña una trabajadora en situación de lactancia natural debe incluir, por un lado, un examen de riesgos con carácter general y, por otro lado, un análisis de los riesgos específicos que tengan en cuenta la situación individual de la trabajadora. En la evaluación deben incluirse, además, los peligros potenciales de los puestos de trabajo para este colectivo de riesgo con independencia de que estén siendo ocupados o no en ese momento por trabajadoras lactantes ${ }^{45}$.

En definitiva, conforme a la normativa y doctrina jurisprudencial española anterior a los pronunciamientos del TJUE, resulta obligatorio identificar el riesgo al que se encuentra expuesta la trabajadora lactante y que éste sea específico, es decir, relevante para la seguridad y salud de la trabajadora y su hijo, debiendo reunir los requisitos establecidos por la jurisprudencia respecto a la determinación de su naturaleza, características, duración de la exposición al riesgo, etc. En tal sentido, el empresario, directamente o a través de los servicios de prevención, debe realizar una correcta evaluación de los riesgos que presenta el concreto puesto de la trabajadora en situación de lactancia natural.

Dicha evaluación, conforme a las Directrices establecidas en la Comunicación de la Comisión de 5 de octubre de $2000^{46}$ constituye un "examen sistemático de todos los aspectos de la actividad profesional" y abarca, al menos, tres momentos distintos ${ }^{47}$ : primero, la identificación del riesgo o peligro

${ }^{41}$ Dicho precepto establece en su apartado 1. a) "El empresario deberá realizar una evaluación inicial de los riesgos para la seguridad y salud de los trabajadores, teniendo en cuenta, con carácter general, la naturaleza de la actividad, las características de los puestos de trabajo existentes y de los trabajadores que deban desempeñarlos. Igual evaluación deberá hacerse con ocasión de la elección de los equipos de trabajo, de las sustancias o preparados químicos y del acondicionamiento de los lugares de trabajo. La evaluación inicial tendrá en cuenta aquellas otras actuaciones que deban desarrollarse de conformidad con lo dispuesto en la normativa sobre protección de riesgos específicos y actividades de especial peligrosidad. La evaluación será actualizada cuando cambien las condiciones de trabajo y, en todo caso, se someterá a consideración y se revisará, si fuera necesario, con ocasión de los daños para la salud que se hayan producido".

42 Este RD fue modificado por el RD 289/2009, de 22 de marzo. La evaluación de riesgos debe orientarse a la situación de lactancia materna de la trabajadora y ajustarse a las Directrices recogidas en la Comunicación de la Comisión de 5 de octubre de 2000, adaptadas conforme al art.3 apartado 2 de la Directiva 92/85/CEE. La jurisprudencia comunitaria señala que la evaluación de riesgos constituye un examen sistemático y periódico de todos los aspectos de la actividad profesional que abarca la identificación de los peligros, la identificación de las categorías de trabajadoras expuestas a los riesgos y la evaluación cualitativa y cuantitativa de los mismos. Considera a ésta "la fase más delicada del proceso ya que la persona que lleva a cabo la evaluación debe ser competente y tener debidamente en cuenta la información pertinente [...] a la hora de aplicar los métodos adecuados para decidir si el peligro detectado conlleva efectivamente una situación de riesgo para los trabajadores". Véase la STJUE de 19 de octubre de 2017, C-535/2015.

43 Véase, por ejemplo, NTP 542: tóxicos para la reproducción femenina.

44 STS de 21 de septiembre de 2011, rec. n' 2342/2010.

45 En el mismo sentido, R. Poquet Catalá, "Inexistencia de evaluación de riesgos...”, ob. cit., pág. 184.

46 Bruselas, 05.10.2000 COM (2000) 466 final.

47 Sobre estas Directrices véase a J. Franco GonZÁlez, "Directrices para la evaluación de los agentes químicos, físicos o biológicos, así como los procedimientos industriales considerados como peligrosos para la salud o la seguridad de la trabajadora embarazada, que haya dado a luz o en período de lactancia (en aplicación de la Directiva 92/85/CEE, del Consejo. Comentarios a la Comunicación de la Comisión de las Comunidades Europeas", Revista del Ministerio de Trabajo y Asuntos Sociales $\mathrm{n}^{\mathrm{0}} 67$, págs. 287 y ss. 
(agentes físicos, químicos y biológicos ${ }^{48}$; procedimientos industriales ${ }^{49}$; movimientos y posturas; fatiga mental y física ${ }^{50}$ y otras cargas físicas y mentales; dos, la identificación de las categorías de trabajadoras expuestas a esos peligros; y tres, la evaluación cualitativa y cuantitativa de los riesgos (apartado 48). Los riesgos detectados en la evaluación, genéricos y específicos, deben incluirse en el plan de prevención de riesgos de la empresa, así como las medidas para prevenirlos, pero sólo el riesgo específico y no meramente genérico ha permitido activar, hasta ahora, las medidas previstas por el legislador español para preservar la seguridad y salud de la trabajadora lactante y su hijo.

21. Ahora bien, nuestro Tribunal Supremo, ha dado un giro a tales requerimientos pues, acogiendo la doctrina jurisprudencial europea, entiende recientemente en su sentencia de 26 de junio de $2018^{51}$ que la falta de evaluación específica no debe afectar negativamente a la trabajadora lactante. Parece abandonar el requerimiento de la evaluación específica si existe una evaluación genérica del riesgo de la que es posible deducir indicios de riesgo para la trabajadora lactante o su hijo y, además, no se contrarrestan tales indicios por la empresa, el INSS o la Mutua con la que está concertada la cobertura de los riesgos profesionales ${ }^{52}$. La trabajadora lactante podrá, en su caso, aportar los indicios pertinentes sobre existencia de riesgos para su seguridad y salud o la de su hijo, provocando, en su caso, la inversión de la carga de la prueba. Es más, entiende el TS que, pese a no existir una evaluación específica "la constatación del listado de riesgos comunes de dicha actividad basta [...] para sostener que ninguna duda cabe del efecto que algunos de ellos tiene sobre la lactancia materna". Al respecto, es suficiente la lectura de la propia evaluación de riesgos genérica "para deducir la concurrencia de circunstancia que, aceptada su incidencia sobre cualquier trabajador, tienen particular repercusión en el caso de la mujer en período de lactancia y, frente a tal apreciación que cabe hacer sin necesidad de especiales conocimientos técnicos -así, por ejemplo, respecto del riesgo de contagio por contacto con fluidos humanos diversos-, habrá de ser la parte que niega la existencia de la situación de riesgos durante la lactancia natural la que haya de desarrollar la actividad probatoria en contrario". La evaluación específica del riesgo para la lactancia natural deja así de representar un obstáculo insalvable para la trabajadora disconforme con la misma.

22. Tras el paso previo de evaluación inicial y específica o complementaria, el art. 26 LPRL prevé distintas medidas de carácter sucesivo para evitar el riesgo para la lactancia natural. Estas medidas son secuenciales y abarcan la adaptación de las condiciones laborales o el tiempo de trabajo, la movilidad funcional - ordinaria o extraordinaria ${ }^{53}$ - e, incluso, la suspensión del contrato de trabajo que permitirá, en su caso, el acceso a la prestación de seguridad social por la contingencia de riesgo durante

48 Por ejemplo, peligros derivados de campos y ondas electromagnéticos; exposición al ruido; exposición a las vibraciones mecánicas; riesgo de atmósferas explosivas; exposición a los agentes químicos; peligros que resultan de las radiaciones ionizantes; exposición a agentes carcinogénicos y mutágenos; exposición a agentes biológicos y exposición al amianto, principalmente. Por lo que se refiere específicamente a los agentes químicos, la Directiva 67/548/CEE del Consejo, modificada en último término por la Directiva 2000/33/CE de la Comisión, relativa a la aproximación de las disposiciones legales, reglamentarias y administrativas en materia de clasificación, embalaje y etiquetado de sustancias peligrosas prevé las siguientes frases de riesgo para las sustancias y los preparados: - posibilidad de efectos irreversibles (R40) - puede causar cáncer (R45) - puede causar alteraciones genéticas hereditarias (R46) - puede causar cáncer por inhalación (R49) - puede causar daños al feto (R61) - posible riesgo de daño para el feto (R63) - puede causar daño a los lactantes (R64) En el marco de la evaluación de las sustancias existentes y de los trabajos del SCOEL (Scientific Committee for Occupational Exposure Limits), la Comisión también ha elaborado una serie de documentos que abordan en parte este tema.

49 Por ejemplo, el análisis, evaluación y control de riesgos específicos como: máquinas, equipos, instalaciones y herramientas; lugares y espacios de trabajo; manipulación, almacenamiento y transporte, etc

50 Incluye la evaluación a las disciplinas de la ergonomía y la psicosociología aplicada. Un ejemplo podría ser el Método ERGOMATER/IBV, el cual pretende dar una respuesta clara y práctica a la singularidad legislada en cuanto a los requisitos ergonómicos para la protección de la maternidad en tareas con carga física, diseñado por el Instituto de Biomecánica de Valencia, en colaboración con Muvale, Unión de Mutuas y la Asociación Salus Vita.

51 Rec. $n^{\circ} 1398 / 2016$.

52 En el mismo sentido, F. NAVARro Nieto, "Riesgos laborales por lactancia natural y discriminación por razón de sexo: novedades en la jurisprudencia", La Ley Digital 12643/2018, pág. 9.

53 STS de 22 de noviembre de 2011, -rec. no 306/2011- y STS de 21 de marzo de 2013, - rec. $\mathrm{n}^{\circ}$ 1563/2012. Sobre esta materia véase M. SÁNCHEZ LindE, "Adaptación del puesto de trabajo y traslado en la situación de riesgo durante la lactancia", Diario La Ley no 8918, pág. 4. 
la lactancia natural. El hecho determinante de la prestación es, por tanto, la concurrencia de un riesgo no evitable para la lactancia natural -determinado hasta ahora tras la identificación del riesgo específico en la concreta actividad desempeñada por la trabajadora lactante- y la imposibilidad de exigir al empresario, de manera objetiva o técnicamente posible, la adopción de medidas preventivas del riesgo.

23. En todo caso, el acceso a la prestación pública es el último recurso al que acudir para evitar el riesgo a la salud de la trabajadora lactante y su hijo y no depende de una opción empresarial adoptada a su libre albedrío pues, en tal caso, nunca se articularían medidas que implican una carga empresarial sino que se acudiría, directamente, a la suspensión contractual sin coste o carga para el empresario.

\section{La dispensa de trabajo y la prestación por riesgo durante la lactancia natural.}

24. Los arts. 188 y 189 de la LGSS se encargan de la regulación de la prestación por riesgo durante la lactancia natural, remitiendo al art. 26.4 de la LPRL la fijación de los requisitos previos que debe realizar el empleador para preservar la seguridad y la salud de la trabajadora lactante antes de lucrar la prestación económica por dicha causa. Se dispone que esta prestación es la situación en la que se encuentra una trabajadora durante la suspensión de su contrato de trabajo por la existencia de algún riesgo para ella o para su hijo lactante menor de nueve meses en los casos en que debiendo cambiar de puesto de trabajo por afectar negativamente a su salud o en la del hijo a otro compatible con su estado -sin merma de su retribución-, dicho cambio no resulte posible técnicamente o no puede razonablemente exigirse por motivos justificados (art. 188 LGSS) ${ }^{54}$. No se incluyen en la situación protegida los riesgos o patologías que puedan influir negativamente en la salud de la trabajadora o en la de su hijo cuando no está relacionada con agentes, procedimientos o condiciones de trabajo del puesto de trabajo desempeñado.

25. De la normativa y la doctrina judicial se desprende que los requisitos previstos para lucrar la prestación se exigen de manera sucesiva, siendo la prestación económica el último recurso para preservar la seguridad y salud de la trabajadora y/o su hijo. La dispensa de trabajo que se produce en caso de lucrar la prestación económica por riesgo durante la lactancia natural tiene, por tanto, carácter subsi-

54 El disfrute de la prestación económica por riesgo durante la lactancia natural se predica únicamente de las mujeres trabajadoras en período de lactancia natural. Éstas pueden ser trabajadoras por cuenta ajena, por cuenta propia, o funcionarias incluidas en el Régimen General de la Seguridad Social e incluidas en el ámbito de aplicación del Estatuto Básico del Empleado Público. Para las funcionarias incluidas en la Mutualidad de Funcionarios Civiles del Estado véase el art. 22 del Real Decreto Legislativo 4/2000, de 23 de junio, por el que se aprueba el Texto Refundido de la Ley de Seguridad Social de los funcionarios públicos. Esta disposición señala que "1. Las situaciones de riesgo durante el embarazo o durante la lactancia natural de hijos menores de 9 meses tendrán la misma consideración que la situación de incapacidad temporal derivada de enfermedad profesional, por lo que no requerirán de periodo de carencia y sus contenidos asistenciales serán los previstos para esta situación. 2. La concesión de las licencias por riesgo durante el embarazo o durante la lactancia natural y sus posibles prórrogas corresponderá a los órganos administrativos con competencia en materias de gestión de personal. 3. Reglamentariamente se establecerá la forma y contenidos de la evaluación médica del riesgo para la salud de la madre, hija o hijo, y de la acreditación de que este riesgo deriva de las funciones habituales del puesto de trabajo, así como que el riesgo no es evitable mediante la modificación temporal de funciones o puesto o el traslado provisional de la funcionaria a otro puesto de trabajo, de conformidad con lo establecido en el artículo 26 de la Ley 31/1995, de 8 de noviembre, de Prevención de Riesgos Laborales. 4. En las situaciones a que se refiere este artículo, los derechos económicos en toda la duración de la licencia serán los establecidos en el artículo 21 precedente con la particularidad de que la prestación económica equivalente al subsidio por incapacidad temporal consistirá en un subsidio a cargo de la Mutualidad General de Funcionarios Civiles del Estado en cuantía igual al 100 por ciento de las retribuciones complementarias devengadas en el tercer mes de licencia. Véase, también, la Orden PRE/1744/2010, de 30 de junio por el que se regula el procedimiento de reconocimiento, control y seguimiento de las situaciones de IT, riesgo durante el embarazo y riesgo durante la lactancia natural en el Régimen Especial de la Seguridad Social de los funcionarios civiles del Estado. La extensión de la protección a las funcionarias incluidas en los regímenes mutualistas se produjo por la modificación de la Ley de funcionarios civiles del Estado, aprobada mediante el Decreto 315/1964, de 7 de febrero, por la LO 3/2007, de 22 de marzo, para la igualdad efectiva de mujeres y hombres. Respecto de las funcionarias incluidas en la Mutualidad Judicial (MUGEJU) véase el RDL 3/2000, de 23 de junio, por el que se aprueba el texto refundido de las disposiciones vigentes sobre el Régimen Especial de Seguridad Social del personal al servicio de la Administración de Justicia; para las lactantes incluidas en el ISFAS, véase el RD 1026/2011, de 15 de julio, por el que se aprueba el Reglamento General del personal al servicio de las Fuerzas Armadas (BOE 4 de agosto). 
diario. Así, los pasos previos para proteger la seguridad y salud de la trabajadora lactante y/o de su hijo son los siguientes: primero, la identificación de los riesgos específicos para la trabajadora en situación de lactancia natural; segundo, la imposibilidad de adaptar las condiciones de trabajo del puesto específico; tercero, la imposibilidad de cambio de la trabajadora lactante a un puesto de la misma o diferente categoría que no tenga esos riesgos o con niveles de riesgo tolerables o controlados y, por último, la prestación económica por riesgo durante la lactancia que provoca la suspensión contractual con la correspondiente dispensa de trabajo. En concreto, para acceder a la prestación económica por riesgo durante la lactancia natural se deben cumplir de manera sucesiva los siguientes requisitos: 1) constatar la existencia de un riesgo que pueda influir negativamente en la salud de la lactante o su hijo ex art. 26.4 LPRL; 2) adaptar las condiciones de trabajo cuando no sea posible eliminar el riesgo ex art. 26.2 LPRL y 3) trasladar a la trabajadora a un puesto o función diferente y compatible con su estado aplicando los principios propios de la movilidad funcional ex art. $26.23^{\circ}$ LPRL o, incluso, a un puesto de trabajo no correspondiente a su grupo o categoría ex art. 26.2.3 ${ }^{\circ} \mathrm{LPRL}^{55}$.

26. Pero la prestación por riesgo durante la lactancia disfruta de una regulación estricta no sólo por el carácter subsidiario de la misma respecto de otras medidas protectoras establecidas en la LPRL sino, como ya se ha indicado, por las dificultades que plantea la acreditación del riesgo específico para la lactancia natural cuando se ha hecho la correspondiente evaluación de riesgos. Hasta el momento, el reconocimiento de la prestación por riesgo durante la lactancia se ha condicionado en nuestro ordenamiento al cumplimiento de un cauce procedimental complejo que requiere algo más que la mera alegación del padecimiento de riesgos genéricos asociados a un concreto puesto de trabajo. Dejar a la trabajadora el peso de acreditar la existencia de riesgo para su salud o la de su hijo en tales casos implicaba una situación injusta y compleja para la misma al recaer sobre ella no sólo el peso de la prueba sino también el rechazo que sufre por su particular situación relacionada con la maternidad. Es por ello que, aunque tardía, resulta bienvenida la nueva doctrina del TJUE en materia probatoria, ya acogida por el TS en su sentencia de 26 de junio de 2018 al señalar que "en supuestos en que la evaluación de riesgos no perfile de modo específico la incidencia de los riesgos del puesto de trabajo durante el período de lactancia, resultaría contrario al derecho a la igualdad y no discriminación de la trabajadora que se negara la posibilidad de acreditar que efectivamente los riesgos sí constatados con carácter general puedan tener una incidencia específica durante el período de lactancia”. Esta posibilidad provocará, sin duda, un más fácil acceso a la prestación por riesgo durante la lactancia natural cuando se hayan agotado las medidas previas establecidas en la LPRL para evitar el riesgo.

\section{La certificación médica del riesgo}

27. La situación de riesgo durante la lactancia natural se produce en el caso de trabajadoras lactantes que ocupan un puesto de trabajo que, conforme a la evaluación de riesgos efectuada por su empresa, presenta un riesgo para el recién nacido o para la lactante -de carácter físico o psicosocial-, y así se certifica por los Servicios Médicos del Instituto Nacional de la Seguridad Social o por las Mutuas -a través de un Informe del médico del Servicio Nacional de Salud que asiste a la trabajadora lactante-. La certificación del riesgo específico para la lactancia, la imposibilidad de modificar las condiciones de trabajo del puesto desempeñado y la ausencia de puesto compatible con su estado provoca la dispensa del trabajo, colocando a la trabajadora en situación de suspensión contractual ex art. 45 ET, que le permitirá lucrar, posteriormente, el subsidio por riesgo durante la lactancia natural.

28. El cumplimiento del requisito formal de la acreditación del riesgo resulta fundamental para articular las diferentes medidas previstas en caso de riesgo para la seguridad y salud de la trabajadora lactante y/o su hijo. En tal sentido, la certificación médica de la lactancia natural es un requisito sine qua non para adoptar cualquiera de las medidas previstas en la norma, motivo por el que ésta requiere el certificado médico realizado por los servicios médicos del INSS o de la Mutua con la que la empresa

55 SSTS de 18 de marzo de 2011 -rec. n ${ }^{\circ}$ 1863/10-, de 23 de enero de 2012 -rec. n $^{\circ}$ 1706/11-, entre otras. 
tenga concertada la cobertura de los riesgos profesionales, así como el informe médico del Servicio Nacional de Salud que asista a la trabajadora lactante y a su hijo. La certificación del riesgo conforme a los resultados de la evaluación y el preceptivo certificado de los servicios médicos funcionan como presupuesto habilitante de las medidas protectoras para la seguridad y salud de la trabajadora lactante. La ausencia de tales certificaciones e informes acreditando el riesgo para la salud y seguridad de la trabajadora lactante impiden el acceso de la mujer a las medidas preventivas que prevé la ley y, por tanto, a la posibilidad de obtener una dispensa de trabajo y el acceso a la prestación por riesgo durante la lactancia natural. Es, precisamente, este requisito formal el que, tras la STJUE de 19 de octubre, C-531/15, se interpreta de manera amplia y flexible al permitir cuestionar, de manera sobrevenida, la evaluación de riesgos efectuada por el empleador respecto del puesto de trabajo desempeñado por la trabajadora lactante y provocar, en consecuencia, un importante cambio en orden a obtener la dispensa del trabajo y a percibir la correspondiente prestación de seguridad social

Así, conforme a la doctrina jurisprudencial comunitaria ya no es suficiente la mera declaración de 〈apta〉 para el puesto de trabajo o la declaración empresarial de que el puesto está "exento de riesgo" para dar veracidad absoluta a dichos documentos, pues la nueva distribución de la carga de la prueba vincula directamente la protección frente al riesgo en el puesto de la trabajadora lactante con la discriminación por razón de sexo, circunstancia que obligará el empleador a demostrar fehacientemente la inexistencia de riesgos para la lactancia natural o, en su caso, que la evaluación de riesgos se realizó adecuadamente y sin basarse en "meros documentos genéricos sobre riesgos". La interpretación rigorista que hasta ahora se había realizado del valor de los informes presentados por la empresa y el Servicio Nacional de Salud deja paso a una valoración más flexible en la apreciación del riesgo y, por tanto, a la admisión de nuevos elementos de prueba que aporten indicios de la vulneración del principio de igualdad por causa de la falta la protección por riesgo durante la lactancia natural.

29. Se producen así dos novedades importantes en el ámbito procesal: primero, el tránsito de una presunción iuris et de iure a una presunción iuris tantum de veracidad en relación con los certificados aportados por el empresario y el Servicio Nacional de Salud y, segundo, la inversión de la carga de la prueba en los supuestos en que la trabajadora lactante aporte indicios suficientes que planteen dudas sobre la correcta evaluación de riesgos de su puesto de trabajo y, con ello, de la vulneración del principio de igualdad de sexo. Los nuevos elementos de prueba deberán ser, obviamente, imparciales y específicos respecto a los riesgos de la trabajadora lactante. Se abre la puerta, incluso, a que la trabajadora lactante, pese a la existencia de condiciones laborales óptimas, pueda acreditar formalmente la existencia de riesgos psicosociales derivados de la organización del trabajo (v. gr. stress, agobios, aislamiento, carga mental o agotamiento emocional...), dando a éstos un nuevo impulso como factores psicosociales en la salud laboral.

\section{Nuevo reto: los 〈riesgos psicosociales〉 de la trabajadora lactante y su problemática identificación}

30. La reciente doctrina judicial europea y nacional abre la puerta a tomar en consideración a los denominados 〈riesgos psicosociales〉 asociados a la lactancia natural que, por su propia imprecisión, hacen difícil su concreción, evaluación y eliminación pero que se asientan con especial fuerza para las trabajadoras en situación de lactancia natural, sobre todo, en ciertos sectores de actividad como el sanitario o el aeronáutico.

31. Ya la OIT demostró en la década de los años ochenta su preocupación por los riesgos psi$\operatorname{cosociales}^{56}$, advirtiendo más recientemente, que uno de los factores de riesgo psicosocial más importante es la inseguridad contractual e, incluso, las formas atípicas de trabajo ${ }^{57}$ que generan situaciones de angustia y estrés en los trabajadores. No obstante, pese al interés de la OIT y otros organismos

56 La primera publicación oficial sobre estos riesgos fue realizada por la OIT en 1984: "Los Factores Psicosociales en el Trabajo: Reconocimiento y Control"; De la Comisión Europea puede verse el documento ¿La sal de la vida o el beso de la muerte) en 1999 y el Acuerdo Marco sobre estrés.

57 OIT, Non-standad form o employment, Ginebra 2015, págs. 28-29. 
internacionales en los riesgos psicosociales, han faltado actuaciones específicas capaces de garantizar su efectiva prevención ${ }^{58}$.

32. Por su parte, la Exposición de Motivos de la LPRL señala que el objetivo de la misma va dirigido a abordar, de manera global y coherente, el conjunto de problemas derivados de los riesgos relacionados con el trabajo. El riesgo laboral se define en el art. 4 de la ley como la posibilidad de que un trabajador sufra un determinado daño derivado del trabajo, a la vez que el apartado 7 de dicho artículo considera como «condición de trabajo〉 cualquier característica del mismo que pueda tener una influencia significativa en la generación de riesgo para la seguridad y salud del trabajador. Ello incluye, a juicio de la doctrina especializada en esta materia, a los riesgos psicosociales (clásicos, como el estrés, o emergentes, como la carga mental o inseguridad laboral), entendidos como "las alteraciones que puedan afectar la salud psicológica de las personas que responden a las condiciones presentes en una situación laboral, directamente relacionadas con la organización del trabajo, con el contenido de la tarea e incluso con el entorno, que tiene capacidad de afectar al desarrollo del trabajo" ${ }^{59}$.

33. La ausencia de regulación normativa europea y nacional sobre estos riesgos y la falta de actuaciones concretas en orden a su identificación, evaluación y protección no impiden ver, en la práctica, el alto grado de incidencia de los mismos en la salud laboral de la trabajadora lactante, los cuales se elevan exponencialmente cuando conectan, entre otros factores, con las tecnologías de la información y comunicación, con trabajos flexibles, con trabajos temporales, con cambios en la organización productiva o, incluso, con situaciones de crisis económicas .

34. Desde el ámbito de la medicina ya se había advertido que "cuando los factores organizacionales y psicosociales de las empresas son disfuncionales provocan respuestas de inadaptación, de tensión, respuestas psicofisiológicas de estrés que pasan a ser factores psicosociales de riesgo o de estrés" ${ }^{60}$. Los factores psicosociales con probabilidad de afectar negativamente a la salud y el bienestar del trabajador son factores de riesgo por actuar como factores desencadenantes de tensión y de estrés laboral, lo que implica que todos los riesgos deben identificarse, eliminarse o evitarse a través de una correcta evaluación de los mismos ${ }^{61}$.

35. En todo caso, los factores psicosociales pueden alcanzar la consideración de factores de riesgo cuando causan un daño para la salud o la integridad física, psíquica o moral de las trabajadoras lactantes, pudiendo deberse ello a la percepción de la trabajadora lactante de su propia situación, de su capacidad y de sus necesidades. La generación del daño a la salud se conecta así con las tareas que integran su actividad laboral, el tiempo de trabajo, el ritmo de trabajo, la carga mental, etc., siendo el estrés laboral un problema que, por las dificultades que plantea para el mantenimiento de la lactancia natural, afecta sobremanera a estas trabajadoras en ese particular momento de su ciclo biológico.

36. Todos estos riesgos adquirirán, previsiblemente, un mayor protagonismo en los mecanismos de tutela preventiva de la trabajadora lactante y su hijo, debiendo establecerse, por un lado, la valoración específica de tales riesgos y, por otro lado, la implementación de sistemas probatorios flexibles que obliguen al empleador a demostrar la ausencia de tales riesgos para estas trabajadoras en situación

58 Al respecto, M ${ }^{a}$ T. Igartua Miró, "Los riesgos psicosociales...”, ob., cit., pág. 46.

59 Ma T. Igartua Miró, "Los riesgos psicosociales: evaluación y prevención...”, ob. cit., pág. 48.

60 CA.Giner Alegría, "Evaluación de riesgos psicosociales en el trabajo", Anales de Derecho n 30, Servicio de Publicaciones de la Universidad de Murcia, 2012, pág. 255; F. MAnsilla IzQuiERdo, "El riesgo psicosocial en el trabajo: una realidad emergente", Revista de la Asociación Española de Neuropsiquiatría, no 89, 2004, pág. 3; Mª E. Londoño Londoño, "Influencia de los factores psicosociales en la salud percibida, el burnout y compromiso del personal”, ORP Journal, nº 4, 2015, pág. 1 y ss.

${ }_{61}$ Entre los distintos métodos para evaluar el riesgo psicosocial se encuentran los siguientes: a) Método de evaluación de riesgos psicosociales PSICO; b) Método ISTA21; c) Cuestionario del método de evaluación de factores psicosociales (Instituto Nacional de Seguridad e Higiene en el Trabajo); d) Cuestionario de factores psicosociales (Instituto Navarro de Salud Laboral y e) Cuestionario multidimensional DECORE. Sobre ellos, véase a C.A. GinER AlEgríA, "Evaluación de riesgos psicosociales en el trabajo", ob. cit., págs. 260-266. 
vulnerable. No se trata, en tal caso, de establecer la denominada 〈prueba diabólica〉 al empleador sino de acreditar por parte de éste que su comportamiento o las decisiones adoptadas tras la evaluación de riesgos específicos obedece a motivos objetivos, razonables y ajenos a cualquier móvil discriminatorio o lesivo de derechos fundamentales. No obstante, cuando no sea posible demostrar la ausencia de riesgo y/o de móvil discriminatorio, se deberá facilitar a la trabajadora lactante el acceso a las medidas protectoras de su seguridad y salud, incluyendo la dispensa de trabajo mediante la suspensión contractual y el acceso a la prestación por riesgo durante la lactancia natural.

37. En esta línea, algunos pronunciamientos judiciales han planteado un nuevo horizonte respecto de los denominados 〈riesgos psicosociales en el trabajo〉 que, como indica la doctrina especializada, no son factores secundarios o complementarios para la seguridad y salud sino sustantivos y de creciente importancia en la estructura actual del trabajo y sus características organizacionales ${ }^{62}$. Estos riesgos tienen una evidente repercusión en la salud de los trabajadores en general y se asocian a factores como la globalización, el aumento del sector servicios, la generalización del uso de la tecnología tanto para producir como para vigilar y controlar al trabajador, y a los cambios organizacionales que afectan, entre otras condiciones laborales, al trabajo nocturno, al tiempo de trabajo o al trabajo a turnos ${ }^{63}$. Pero tales condiciones laborales pueden generar mayor situación de vulnerabilidad o elemento de resiliencia para las trabajadoras lactantes (ej. estrés laboral), cuya particular situación puede generar una mayor exposición a tales riesgos, obligando al empresario a afrontar la eliminación del riesgo conforme a la LPRL (arts. 4 y 15).

38. La evaluación empresarial de los riesgos psicosociales mencionados, que presentan la complejidad de venir determinados por factores personales y contextuales de la trabajadora que dificultan la identificación del riesgo específico, podría ser inadecuada o incompleta y permitir a la lactante aportar indicios de la existencia del riesgo para su salud o la de su hijo mediante instrumentos de prueba adecuados -v. gr. nuevo informe o certificación médica distinta de la realizada por los servicios médicos del INSS o las Mutuas-, que trasladarán al empresario la obligación de demostrar la correcta realización de la evaluación de riesgos para la lactante y su hijo y la ausencia de móvil discriminatorio. Téngase en cuenta que el Tribunal Supremo ya ha admitido que "el riesgo se puede apreciar cuando los horarios de trabajo resultan inadecuados con los periodos regulares de alimentación del lactante" pero "siempre y cuando la incompatibilidad de la 〈toma〉 directa no pudiera paliarse con la extracción de la leche" Para el TS, en estos casos, debe atenderse "a las particulares circunstancias de que el lugar en que se desarrollaba la prestación de servicios impedía tanto la extracción de la leche como su conservación (tripulantes de cabina de aviones)", aunque deja abierta la posibilidad de acreditar "que la extracción fuera, en el supuesto concreto, método no aconsejable para la salud de la madre o del lactante"65. Con la nueva doctrina, se puede flexibilizar esta posición pues la dificultad que representa la extracción de la leche materna y sus posibles consecuencias negativas para la salud de la lactante (ej. mastitis, estrés, dolor, perdida de la calidad y cantidad de la leche...) pueden abocar al reconocimiento del riesgo ${ }^{66}$.

39. Se reabre con fuerza, sin duda, la controversia sobre la turnicidad y nocturnidad como riesgos "específicos" para las trabajadoras lactantes, pese a que nuestro TS entendió en varias ocasiones que ni uno ni otro son riesgos contemplados en la normativa de prevención. Así, la doctrina judicial española entendió en alguna ocasión que ni la turnicidad ni la nocturnidad, por sí mismos, constituyen

${ }^{62}$ B. Moreno Jiménez, “Olvido y recuperación de los factores psicosociales en la salud laboral”, Arch Prev Riesgos 2000; 3 (1), pág. 3.

${ }_{63}$ Véanse las SSTS de 24 de abril de 2012 -RJ 2012, 5116-, de 21 de junio y 22 de noviembre de 2012 -RJ 2012/8964 y 2013/355 respectivamente- y de 21 de marzo de 2013 -RJ 2013/3825-.

64 STS de 21 de marzo de 2013, RJ 2013/3825.

65 STS de 21 de marzo de 2013, RJ 2013/3825.

66 La STS de 26 de junio de 2018 -rec. no 1398/2016-, señala que "no sólo el listado de los Anexos del Reglamento no es exhaustiva sino que, además, la delimitación de la contingencia en el caso de la lactancia natural no resulta en absoluto fácil, porque lo que se busca, en suma, es la constatación de que el amamantamiento se ve dificultado o impedido por el mero desempeño de la actividad laboral". 
un elemento de riesgo añadido pero, recientemente, el TS puntualiza que la valoración como riesgos de tales condiciones laborales no se excluyen por el mero hecho de no encontrarse en el Anexo VIII del Reglamento de Prevención de Riesgos Laborales, ya que éstos son meramente orientativos y no pueden alzarse como el criterio decisivo para valorar la existencia de riesgos ${ }^{67}$. En esta línea, la STJUE de 19 de septiembre de 2018, C-41/17, considera que cuando la trabajadora lactante desarrolla una parte de las funciones laborales en horario nocturno debe calificarse como "trabajador nocturno" en el sentido de la Directiva 2003/88/CE del Parlamento Europeo y del Consejo de 4 de noviembre de 2003 relativa a determinados aspectos de la ordenación del tiempo de trabajo y, por tanto, resulta de aplicación el art. 7 de la Directiva $92 / 85^{68}$, sin que la trabajadora lactante que se encuentra en tal situación pueda estar en una situación más desfavorable que la que se encuentra en el art. 4 de la misma. La jurisprudencia europea entiende que, en tal supuesto, debe aplicarse también la protección del art. 19 de la Directiva 2006/54 e invertir, en consecuencia, la carga de la prueba.

El objetivo de las normas internacionales y nacionales desacreditan, por tanto, la rigurosa posición de los Tribunales de Justicia españoles a este respecto pues no cabe duda que el estrés aparejado a la lactancia materna se incrementa notablemente en los supuestos de turnicidad y nocturnidad debiendo ser el informe médico el que, en su caso, acredite dicho extremo ${ }^{69}$.

67 STS de 3 de abril de 2018 - rec. $n^{\circ} 762 / 2017-$

68 “Artículo 7 Trabajo nocturno 1. Los Estados miembros tomarán las medidas necesarias para que las trabajadoras a que se refiere el artículo 2 no se vean obligadas a realizar un trabajo nocturno durante el embarazo o durante un período consecutivo al parto, que será determinado por la autoridad nacional competente en materia de seguridad y salud, a reserva de la presentación, según las modalidades fijadas por los Estados miembros, de un certificado médico que dé fe de la necesidad para la seguridad y salud de la trabajadora afectada. 2. Con arreglo a las legislaciones y/o prácticas nacionales, las medidas contempladas en el apartado 1 deberán incluir la posibilidad: a) del traslado a un trabajo diurno, o b) de una dispensa de trabajo, o de una prolongación del permiso de maternidad cuando dicho traslado no sea técnica y/u objetivamente posible o no pueda razonable mente exigirse por motivos debidamente justificados.

69 Véase al respecto, la Recomendación 95 y Convenio n ${ }^{\circ} 103$ de la OIT. 